\title{
A study of predisposing factors and microbial flora in puerperal sepsis
}

\author{
Tajinder Kaur ${ }^{1 *}$, Sunita Mor ${ }^{1}$, Meenu Puri ${ }^{2}$, Ruchika Sood ${ }^{3}$, Jayati Nath ${ }^{1}$
}

\author{
${ }^{1}$ Department of Obstetrics and Gynaecology, MMIMSR, Mullana, Ambala, Haryana, India \\ ${ }^{2}$ Department of Obstetrics and Gynaecology, Civil hospital Tanda, Punjab, India \\ ${ }^{3}$ Department of Obstetrics and Gynaecology, Civil hospital Palwal, Haryana, India
}

Received: 18 July 2016

Accepted: 09 August 2016

\author{
*Correspondence: \\ Dr. Tajinder Kaur, \\ E-mail: teji1305@gmail.com
}

Copyright: () the author(s), publisher and licensee Medip Academy. This is an open-access article distributed under the terms of the Creative Commons Attribution Non-Commercial License, which permits unrestricted non-commercial use, distribution, and reproduction in any medium, provided the original work is properly cited.

\section{ABSTRACT}

Background: Puerperal sepsis is the third or fourth leading cause of maternal death worldwide with maternal mortality due to infections being as high as $15 \% 6$ with maternal morbidity being $8.1 \% 7$. Meticulous aseptic techniques, modern investigative tools and use of prophylactic antibiotics have reduced the incidence of puerperal sepsis in the developed countries however it still continues as a major cause of maternal morbidity and mortality in the developing countries.

Methods: This was a retrospective study over a period of 18 months from July 2010 to December 2011 which included all the post natal patients admitted in the obstetrics ward of our hospital. All the patients who fulfilled the ICD 10 criteria of puerperal pyrexia were studied for the booking status, parity, mode of delivery, maternal anemia, number of PV examinations and duration of rupture of membranes. In addition vaginal swab culture and sensitivity of these cases was analysed. The results were calculated by statistical analysis and odds ratio calculated with $95 \%$ confidence interval.

Results: The incidence of puerperal sepsis was $8.68 \%$ and was responsible for $60.29 \%$ of cases of puerperal pyrexia. The common predisposing factors were unbooked status, primiparity, caesarean section, anaemia, frequent PV examination and prolonged rupture of membranes. The most common microorganisms in vaginal swab culture and sensitivity were S. aureus (36\%) and E. coli (29.8\%).

Conclusions: Puerperal sepsis is by and large a preventable cause of maternal morbidity and mortality. From our study and review of literature we conclude that early booking of all the antenatal cases, correction of maternal anemia, better aseptic conditions, deferring undue PV examinations, recognition of all the high risk cases and prophylactic administration of ampicillin and gentamycin can go a long way in preventing puerperal sepsis.

Keywords: Microorganisms, Predisposing factors, Puerperal pyrexia, Puerperal sepsis

\section{INTRODUCTION}

International Classification of diseases (ICD-10) defined puerperal pyrexia as a temperature rise above 38.0 degree Celsius maintained over 24 hours from the end of first day till the end of tenth day after childbirth or abortion (excluding the first 24 hours). ${ }^{1}$ The world health organization defined puerperal sepsis as infection of the genital tract occurring at any time between the onset of rupture of membranes or labour and the $42^{\text {nd }}$ day postpartum in which fever and one or more of the following are present;

- Pelvic pain

- Abnormal vaginal discharge

- Abnormal odour or discharge and

- Delay in the rate of reduction of size of uterus. ${ }^{2}$ 
Thus puerperal pyrexia encompasses all cases of puerperal fever and includes patients with puerperal sepsis as well as those with other causes of pyrexia.

Puerperal sepsis is the third or fourth leading cause of maternal death worldwide with maternal mortality due to infections being as high as $15 \%$ with maternal morbidity being $8.1 \% .^{3-7}$

Meticulous aseptic techniques, modern investigative tools and use of prophylactic antibiotics have reduced the incidence of puerperal sepsis in the developed countries however it still continues as a major cause of maternal morbidity and mortality in the developing countries. Various maternal complications of puerperal sepsis include septicaemia, endotoxic shock, peritonitis or abscess formation, decreased future fertility. Fetal complications include poor APGAR score, neonatal septicaemia and pneumonia. The predisposing factors leading to the development of sepsis include: home birth in unhygienic conditions, low socio economic status, poor nutrition, primiparity, anemia, prolonged rupture of membranes, multiple PV examinations, caesarean section and obstetrical manoeuvres. Puerperal sepsis is mostly caused by bacterial infection which can be either endogenous or exogenous.

Our study was aimed to determine the incidence of puerperal pyrexia, predisposing factors, microbial flora and their sensitivity status in tertiary based rural hospital in India.

\section{METHODS}

This was a retrospective study over a period of 18 months from July 2010 to December 2011 which included all the post natal patients admitted in the obstetrics ward of our hospital. All the patients who fulfilled the ICD 10 criteria of puerperal pyrexia were studied for the booking status, parity, mode of delivery, maternal anemia, number of PV examinations and duration of rupture of membranes. In addition vaginal swab culture and sensitivity of these cases was analysed. The results were calculated by statistical analysis and odds ratio calculated with 95\% confidence interval.

\section{RESULTS}

During the study period there were a total of 472 deliveries out of which 68 patients had puerperal pyrexia and 41 cases had puerperal sepsis. Thus the incidence of puerperal pyrexia in our hospital was found to be $14.4 \%$ while that of puerperal sepsis was $8.68 \%$ and puerperal sepsis was responsible for $60.29 \%$ of cases of puerperal pyrexia. $12.79 \%$ of unbooked patients and $7.77 \%$ of booked patients developed puerperal sepsis.

We found that the various predisposing factors for developing puerperal sepsis were unbooked status, primiparity, caesarean delivery, maternal anemia $(\mathrm{Hb}<10$ gm\%), number of PV examinations $>4$ and prolonged rupture of membranes (>18 hours) with Odds ratio of $1.74,2.25,3.34,1.23,1.79,4.11$ respectively (Table 1 ).

Vaginal swab culture reports showed that the most commonly isolated organisms were Staphylococcus aureus and Escherichia coli in $36 \%$ and $24.8 \%$ of cases with maximum sensitivity to gentamycin and ampicillin in $78.05 \%$ and $68.29 \%$ cases respectively (Table 2,3 ).

Table 1: Risk factors: Puerperal Sepsis.

\begin{tabular}{|c|c|c|}
\hline & Present & Absent \\
\hline \multicolumn{3}{|l|}{ Booking status } \\
\hline Unbooked & 11 & 75 \\
\hline Booked & 30 & 356 \\
\hline Total & 41 & 431 \\
\hline \multicolumn{3}{|l|}{ Odds ratio $=1.74$} \\
\hline \multicolumn{3}{|l|}{ Parity } \\
\hline Primipara & 32 & 264 \\
\hline Multipara & 9 & 167 \\
\hline Total & 41 & 431 \\
\hline \multicolumn{3}{|l|}{ Odds ratio $=2.25$} \\
\hline \multicolumn{3}{|l|}{ Mode of delivery } \\
\hline Caesarean delivery & 21 & 103 \\
\hline Vaginal delivery & 20 & 328 \\
\hline Total & 41 & 431 \\
\hline \multicolumn{3}{|l|}{ Odds ratio $=3.34$} \\
\hline \multicolumn{3}{|l|}{ Maternal anemia } \\
\hline Present & 14 & 128 \\
\hline Absent & 27 & 303 \\
\hline Total & 41 & 431 \\
\hline \multicolumn{3}{|l|}{ Odds ratio $=1.23$} \\
\hline \multicolumn{3}{|c|}{ More than 4 PV examinations } \\
\hline Present & 24 & 190 \\
\hline Absent & 17 & 241 \\
\hline Total & 41 & 431 \\
\hline \multicolumn{3}{|l|}{ Odds ratio $=1.79$} \\
\hline \multicolumn{3}{|c|}{$>18$ hours ruptured membrane } \\
\hline Present & 8 & 24 \\
\hline Absent & 33 & 407 \\
\hline Total & 41 & 431 \\
\hline Odds ratio $=4.11$ & & \\
\hline
\end{tabular}

Table 2: Microbial isolates in vaginal flora.

\begin{tabular}{|ll|}
\hline Organism & Percentage \\
\hline Staphylococcus aureus & 36 \\
\hline Escherichia coli & 24.8 \\
\hline Pseudomonas & 21.8 \\
\hline Klebsiella & 18.6 \\
\hline Acinetobacter & 14.4 \\
\hline Mixed & 24.5 \\
\hline
\end{tabular}


Table 3: Sensitivity pattern of microorganisms isolated in vaginal culture.

\begin{tabular}{|ll|}
\hline Antibiotic & Percentage \\
\hline Gentamycin & 78.05 \\
\hline Ampicillin & 68.29 \\
\hline Amikacin & 48.78 \\
\hline Azithromycin & 46.34 \\
\hline Co-trimoxazole & 19.51 \\
\hline Cefixime & 14.63 \\
\hline Ciprofloxacin & 14.63 \\
\hline
\end{tabular}

\section{DISCUSSION}

From our study we found out that the incidence of puerperal sepsis was $8.68 \%$ which was much higher than the earlier reported incidence of $0.78 \%$ Bako B et al in Nigeria. ${ }^{8}$ They also concluded that the various high risk factors for developing puerperal sepsis were primiparity, unbooked status and caesarean delivery which is in accordance with our study. In addition we found out that maternal anemia, more than 4 PV examinations and prolonged rupture of membranes also carried a significantly higher risk of developing puerperal pyrexia as compared to the other subjects similar to Maharaj D et al. ${ }^{9}$

Burrows LJ et al observed that primary caesarean delivery with trial of labour conferred a 21.2-fold increased risk of endometritis compared with spontaneous vaginal delivery. Even without trial of labour, women after primary caesarean delivery were 10.3 times more likely to develop endometritis than after spontaneous vaginal delivery. ${ }^{10}$

This higher risk is present despite the use of prophylactic antibiotics being administered to all the cases of caesarean section, hence the need to review our antibiotic policy. Moreover considering the increasing trend of caesarean section, the incidence of puerperal pyrexia is likely to increase in the coming years. The most common organisms isolated were Staphylococcus aureus and Escherichia coli which is in accordance with the study by Bako B et al. ${ }^{8}$

According to cochrane review 2010, the use of antibiotic prophylaxis reduced the incidence of endometritis by two thirds to three quarters. ${ }^{11}$ The commonly prescribed antibiotics for prevention of puerperal sepsis include an aminoglycoside for coverage of gram negative organism and clindamycin phosphate for coverage of Gram positive and anaerobic organisms. Second or third generation cephalosporins in combination with metronidazole is another popular choice. From our study maximum sensitivity was seen to gentamycin and ampicillin.

Puerperal sepsis is by and large a preventable cause of maternal morbidity and mortality. From our study and review of literature we conclude that early booking of all the antenatal cases, correction of maternal anemia, better aseptic conditions, deferring undue PV examinations, recognition of all the high risk cases and prophylactic administration of ampicillin and gentamycin can go a long way in preventing puerperal sepsis.

\section{CONCLUSION}

Puerperal sepsis is by and large a preventable cause of maternal morbidity and mortality. From our study and review of literature we conclude that early booking of all the antenatal cases, correction of maternal anemia, better aseptic conditions, deferring undue PV examinations, recognition of all the high risk cases and prophylactic administration of ampicillin and gentamycin can go a long way in preventing puerperal sepsis.

\section{Funding: No funding sources}

Conflict of interest: None declared

Ethical approval: The study was approved by the Institutional Ethics Committee

\section{REFERENCES}

1. Dillen JV, Zwart J, Schutte J, Roosmalen JV. Maternal sepsis: epidemiology, etiology and outcome. Curr Opin Infect Dis. 2010;23(3):249-54.

2. Hussein J, Fortney JA. Puerperal sepsis and maternal mortality: what role can new technologies play? Int J Gynaecol Obstet. 2004;85:S52-61.

3. Li XF, Fortney JA, Kotelchuck M, Glover LH. The postpartum period: the key to maternal mortality. Int J Gynaecol Obstet. 1996;54:1-10.

4. Ronsmans C, Graham WJ. Maternal mortality: who, when, where, and why. Lancet. 2006;368(9542):1189-200.

5. Khan KS, Wojdyla D, Say L, Gülmezoglu AM, Van Look PF. WHO analysis of causes of maternal death: a systematic review. Lancet. 2006;367(9516):106674.

6. World health organization and others. The World health report: 2005: make every mother and child count. Geneva. World Health Organization. 2005.

7. Halim A, Utz B, Biswas A, Rahman F, van den Broek N. Cause of and contributing factors to maternal deaths; a cross-sectional study using verbal autopsy in four districts in Bangladesh. BJOG. 2014;121(Suppl 4):86-94.

8. Bako B, Audu BM, Lawan ZM, Umar JB. Risk factors and microbial isolates of puerperal sepsis at the University of Maiduguri Teaching Hospital, Maiduguri, North-eastern Nigeria. Arch Gynecol Obstet. 2012;285(4):913-7.

9. Maharaj D. Puerperal pyrexia: a review. Part I. Obstet Gynecol Surv. 2007;62(6):393-9.

10. Burrows LJ, Meyn LA, Weber AM. Maternal morbidity associated with vaginal versus cesarean delivery. Obstet Gynecol. 2004;103(5 Pt 1):907-12. 
11. Smaill FM, Gyte GM. Antibiotic prophylaxis versus no prophylaxis for preventing infection after cesarean section. Cochrane Database Syst Rev. 2010;(1):CD007482.
Cite this article as: Kaur T, Mor S, Puri M, Sood R, Nath J. A study of predisposing factors and microbial flora in puerperal sepsis. Int J Reprod Contracept Obstet Gynecol 2016;5:3133-6. 